\title{
Research on the Innovative Application of Interactive Teaching Mode in the Post-PC Era
}

\author{
Ning $\mathrm{He}^{1}$, Jiaying $\mathrm{Li}^{2}$ and $\mathrm{Yi}$ Zhou ${ }^{1, *}$ \\ ${ }^{1}$ School of Fashion, Wu Han Textile University, 1 Fangzhi Road, Wuhan, 430073, China. \\ ${ }^{2}$ College of Art and Design Guilin University of Electronic Technology, Guilin, 541004, China \\ *Corresponding author. Email: 494791829@qq.com
}

\begin{abstract}
With the continuous development of society and technology, portable computer and intelligent communication device through cable or wireless Internet service have integrated into people's life under the post-personal computer era. In this new type of social intelligent environment, the traditional interactive teaching mode and methods have been incompatible with present needs. According to the preparation before class, teaching in class, assignments and interaction as well as common intelligent communication equipment and network application methods in the postpersonal computer era, this paper makes analysis and research on the improvement and innovation of teaching method in the "interactive" teaching of distance education method under the influence of post-personal computer era.
\end{abstract}

Keywords: Interactive teaching, Post-PC era, Innovative application, Informatization.

\section{INTRODUCTION}

With the progress and update of science and technology, together with the development of the computer in the third wave of post-personal computer era, humans are moving towards the information society. Combined with a lot of rapid development of Internet technology, such as mobile Internet, cloud computing and the industrial Internet, the popularity and application of technology makes the impact of big data and informatization on the world more and more significant. With the speed of information search and processing more quickly, its operation method is more diverse. The life is gradually moving towards the manmachine-network, individual customization, resource sharing, more convenient form.

\section{DEFINITION AND CHARACTERISTICS OF THE POST-PC ERA}

There is no clear definition of the post-PC era, while the introduction of the post-PC era mostly refers to the explanation from Baidu in the research of related papers. The post-PC era refers to the combination of computer, communication and consumer products technology in the form of 3C (Computer, Communication, Consumer Electronics) products through the Internet into the home. With time as the limit, the AD 2000 is generally taken as a watershed in the history of science and technology. Before this year, it was called the era of Personal Computer, while after this year, it was called the era of post-personal Computer. [1]

Post-PC era than the PC era is more progressive and convenient with its characteristics are very obvious:

(1) the technological device is convenient and interconnected: the traditional PC, such as personal desktop computer, has large volume, while in the Internet connection, it still needs to use cable network. Although it can process information activities and deal with things on the network, there are limitations in the portable transposition. And then in the post PC era, there are $3 \mathrm{c}$ products, like computer, tablet computer, mobile phone, video and audio player hardware or digital audio player. These electronic tools equipment and application diversification give priority to wireless network applications. At the same time, these 3c products can use digital information technology to activate any of these links, enable resource sharing and interconnection between computer communication and consumer electronic products through certain protocols (see Figure 1).

(2) Fast and large data processing: in the post-PC era, cloud computing is the main application of Internet information data. This pattern provides available, convenient, on-demand network access to a 
configurable shared pool of computing resources (resources including networks, servers, storage, applications, services) that can be provided quickly with little administrative effort or interaction with service providers. [2] In the post-PC era, the cloud in cloud computing is a metaphor of a network or the Internet, which has a very large scale and gives the user an unprecedented computing power. Cloud computing supports users in any position, using a variety of terminals to access application service, and cloud storage in the cloud computing has greater storage capacity. In the era of big data information application, information data search and application methods of the Internet are varied and convenient, which provides a variety of technical and theoretical supports for the reform of education methods.

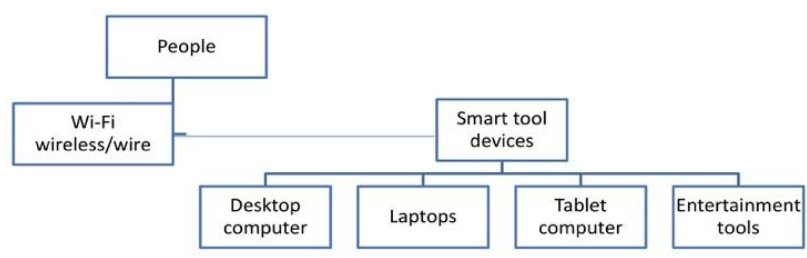

Figure 1. Use of computers, communications and consumer electronics

\section{RESEARCH ON THE PRESENT SITUATION OF INTERACTIVE TEACHING}

The concept of "interactive" teaching was put forward by Palincsar in 1982. In nearly 40 years of development, "interactive" teaching has been continuously innovated, developed and studied. Nowadays, depending on the social environment, technology and economy, it adopts the corresponding teaching mode and method on the basis of the teaching type and the difference between lecturers and students. At present, "interactive" teaching in curriculum teaching mainly appears and is used in the following four forms:

\subsection{Traditional Interactive Teaching}

The most basic feature of the traditional "interactive" teaching is the mutual communication and two-way interaction with objects participating in the activities, that is, the relationship between teachers and students. The word interaction comes from computer terminology. When people use the computer, they can input instructions, and the computer accepts the instructions and makes relative reactions. This process and behavior is called interaction. However, in the traditional "interactive" teaching, the objects of course content interaction are mainly teachers and students who participate in classroom teaching. Because participants are man with so strong subjective initiative. They are purposeful, planned, creative and selective in their activities. Before teaching, the teacher will have certain standard requirements for the content of the course and degree of learning of the students, and then formulate the content, objectives, methods and steps of teaching. Students should take the initiative in learning knowledge and selectively learn the main content of the course. In the course of teaching, teaching is mainly carried out in the way of teacher speaking and students listening. Then, the class is carried out in the form of real-time interaction, such as teacher question-student answer-teacher feedback and student question-teacher answer-student feedback centering on the course content or a certain topic and in combination with the non-realtime interaction, such as test, examination or after-class homework - correcting - feedback. The traditional "interactive" teaching is the direct communication between people, while this teaching form is dominated by teachers, so teachers' interaction with teaching content, methods, steps and body language is the key to the teaching effect.

\subsection{Computer Assisted Instruction}

Computer aided instruction (CAI) is a kind of interactive teaching method derived from the development of computers. Computer Aided Instruction (CAI) refers to the methods and techniques of discussing teaching content, arranging teaching process and teaching training with students in the way of dialogue. [3] This teaching mode is the most popular teaching method in the traditional classroom today. This "man-machine" interactive approach takes two main forms: (1) In the course of teaching, teachers use computers to help or replace them to carry out part of teaching tasks and impart knowledge and skill training to students. Then, through the acquisition of knowledge, students give feedback and discuss with teachers to complete interactive teaching behavior. To carry out this course teaching, the classroom needs to be equipped with large screen projector and multimedia computer, and then the teacher needs to write and create multimedia courseware. The implementation environment of this kind of computer aided instruction can be called multimedia instruction system; (2) There is another one called interactive multimedia teaching system. This kind of teaching environment refers to arranging multiple multimedia computers in the classroom and connecting them through the network. Teachers and students operate their own computers. The teacher's computer is the master computer, which plays multimedia teaching courseware as required. Each computer screen used by students displays teaching content played by the master computer at the same time. The teacher can also monitor the detailed situation of each student's computer through the control platform of the master computer. In these two kinds of teaching environments, the teacher is still the dominant player in the course teaching. Although the computer only plays an auxiliary role, but because of the addition of computer teaching content, it makes some abstract and 
boring knowledge vivid, the teaching process lively, and learning efficiency is greatly improved.

\subsection{Distance Interactive Teaching}

Distance education is different from the face-to-face teaching mode in the classroom, serving the students who are limited by time and space. In the early years, the main method of distance education was through television or CD-ROM videos watched and studied by students. In the post-PC era, with rapid development of computers, intelligent communication devices and the Internet, it has been realized that people can learn according to their learning progress at different times and places, which refers to education and training on demand.[4] People can download various types of teaching resources through the Internet, such as multimedia software, digital audio, video, documents and other data when they are free. When you encounter learning problems, you can turn to the Internet automatic question answering system. Then the teacher can maintain and update the online Q\&A and discussion system and take answers to typical difficult questions in it. At the same time, teachers can also use electronic whiteboard or BBS system to discuss with students through the Internet. And students can also study and discuss through the Internet, so as to realize interactive teaching of learning-feedback-discussion through computer.

\subsection{Interactive Teaching Among Multiple Courses}

The interactive teaching method among multiple courses originates from some teachers' reflection and consideration of curriculum system and teaching methods after they have finished the teaching. Although this method is not popular, some teachers have started to study it. Different from the above three teaching methods, "interactive" teaching among multiple courses is a type of teaching form that integrates multiple courses on the basis of commonality among them, such as the similarity in contents and nature of these courses. For example, Liu Lili pointed out in Preliminary Research on "Interactive" Teaching Mode -- Taking Practice Course Teaching of Product Design as an Example that the "interactive" teaching she studied mainly refers to a kind of communication and learning between disciplines.[5] Taking product practice course as an example, this paper discusses the method of applying this "interactive" teaching mode to teaching practice and achieve practical results.

In the teaching activities of different course contents, the using methods of "interactive" in teaching is also varied. However, the purpose of these teaching methods is the same, which means to mobilize enthusiasm and initiative of students in the learning process and enhance learning efficiency.

\section{RESEARCH ON THE INNOVATIVE APPLICATION OF INTERACTIVE TEACHING MODE IN THE POST-PC ERA}

Because of the influence of technology and information technology, the present "interactive" teaching is no longer limited to teaching, interaction and result verification between teachers and students in the classroom. Especially from 2020, under the influence of the new crown epidemic, the popularization and promotion of online courses enable teachers and students to communicate with each other through computers, mobile phones and other communication devices, creating an interactive teaching process. Nowadays, this interactive teaching mode is being an important teaching mode. Actually, this teaching mode has been taken by some training institutions, which refers to the practice of remote interactive teaching methods in remote teaching and training. For example, the training institution "Zuo Ren China" will put forward course information through WeChat official account, then demonstrate teaching contents or play video remotely through WeChat groups, and finally give teaching feedback and homework guidance in WeChat groups. The essence of development of interactive teaching mode and application in the course is for displaying teaching information more vividly and directly. The teacher's "teaching" can arouse student's "learning" interest, stimulate student's learning motivation, activating and maintaining their subjective initiative. Besides, its development also reflects the development of curriculum education with the Times.

According to the analysis on current situation of "interactive" teaching mode application, this paper conducts research on innovative application of "interactive" teaching mode from four aspects: teaching environment, preparation before class, teaching in class, homework after class and interaction combining with the technological products and Internet in the post-PC era.

\subsection{Teaching Environment}

Teaching environment is a complex system composed of a variety of different factors, which mainly refers to all conditions (including material and mental) that affect school teaching activities.[6] It can be divided into physical environment and psychological environment. Physical environment mainly refers to teaching place and equipment, while psychological environment mainly refers to class atmosphere and teacher-student relations. Under the influence of the post-PC era, the popularity of intelligent communication devices, portable or tablet computers is gradually affecting teaching environment to produce innovative changes. It can be concluded from the following two points:

First, there is a comparative analysis from physics teaching environment. Although traditional interactive 
multimedia classroom has solved the problem of realtime operation display and real-time learning feedback of students in the class, it also has some disadvantages. First of all, the cost of an interactive multimedia classroom for purchase and daily maintenance of equipment is very high, and the classroom is likely to be in short supply when the curriculum of multiple classes is arranged. However, it is mainly a desktop computer and basically has no mobility. So if there is an electrical or equipment malfunction in the classroom, the course basically ends. At the same time, computers in the interactive multimedia classroom are basically public with poor security. The computer is easy to be infected with viruses, which affects its use. Finally, the data of students' assignments cannot be saved in computer to prevent computer from running out of storage space. In the post-PC era, laptops or tablet computers have been popularized and their configuration can basically meet requirements of computer clothing painting. Teachers and students only need to bring their own laptops. It can reflect the convenience of teaching, such as a classroom line problem. Teachers and students can immediately change the classroom, and do not delay teaching progress. There are two places for teachers to choose from when teaching, one is a classroom with a multimedia projector, the other is a classroom with $\mathrm{Wi}$ Fi. During the course of teaching, the computer security performance is higher, because they use their own computers, not easy to be infected by viruses. In addition, students are more comfortable with their own computers, which can save required learning materials and homework. These innovative changes not only optimize school physics teaching environment, but also make teaching and students learning efficiency greatly improved.

Second, from psychological teaching environment for comparative analysis, although teachers and students also have interactive teaching and learning process, the computer used by students in the classroom is not specific to a particular student and is only used in class in the interactive multimedia classroom. Therefore, learning atmosphere in this learning environment will be very short. When the course is over, they need to leave interactive multimedia classroom, and teaching interaction between teacher and student stops. If teachers and students use their own laptops and tablets, there are advantages :(1) easy to carry; (2) for personal use; (3) more familiar with the operation of personal computers; (4) When teaching in class, the teacher can teach as much as possible to the students. After class, students can carry out operation exercises in combination with materials and notes and communicate with teachers by capturing computer screens through chatting tools. All this eases the tension in the teaching atmosphere and deepens the relationship between teachers and students.

It can be seen that popularization and application of intelligent devices and tools in the post-PC era are gradually changing teaching environment in schools, making teachers more student-oriented and better communicating with each other.

\subsection{Preparation Before Class}

Adequate preparation is the prerequisite of a good course. Pre-class preparation mainly refers to the analysis of teaching materials and learning situation, the determination of teaching objectives and tools, writing teaching plans, teaching process design, making courseware and so on. Nowadays, teachers use computers to make electronic documents when making teaching plans and courseware. For example, Word in the Office system is used to make DOC documents for text preparation, while PPT in the Office system is used to make presentations of courseware. In order to prevent courseware and videos from being too old, teachers can combine technology, Internet and intelligent devices and software to independently produce and cut out their own course videos. Such software case videos are not only relevant to the content of the course, but also can be repeated and played quickly or slowly. In the production of video software, Window system computers mostly use software screen recording experts and iOS computers have their own software, such as QuickTime Player. These softwares can be used to directly record entire operation of the computer screen into video, so that students can get a newer and more direct teaching content during learning process.

\subsection{Teaching in Class}

In the course of classroom teaching, the innovation of teaching methods is analyzed according to the change of the teaching environment. In the process of direct, mutual and face-to-face teaching and learning between teachers and students in the classroom, the interaction and discussion between teachers and students can bring the "interactive" teaching into full play. The teacher connects his computer with the projector and students watch teaching contents and software operation demonstration on the projection screen. In order to achieve good learning efficiency, teachers will arrange some time for students to perform some software operations in class, give guidance and answer questions even after class is over. In the post-PC era, devices share resources over networks and wireless $\mathrm{Wi}-\mathrm{Fi}$ networks gradually replace wired networks.

Taking a classroom with Wi-Fi eliminates the need for a projector. Teachers and students only need to connect to the wireless Wi-Fi network and use some remote sharing software to transfer the teacher's computer screen operation live to the students' portable or tablet computer or even smart phone, and then students can watch and learn. There are many of these remote sharewares, such as Tencent conference and Enterprise WeChat. When teachers and students use the same software and enter the same virtual conference room, teachers can click group screen sharing to transfer their screens to students' computers or mobile phones 
(see Figure 3). The application of these hardware or software can make learning environment more optimized and humanized, which teaching contents can be displayed more vividly and directly.

\subsection{Homework and Interaction after Class}

In the post-PC era, the interaction between teachers and students is not limited to the class, because the widespread use of some chatting and tool software allows teachers and students to interact after class and before the formal class. Teachers can use QQ and WeChat to deliver learning materials and homework to students' classes. Teachers can also use cloud storage on the Internet to upload learning materials and videos for students to conduct self-learning after class.

Cloud storage is a professional Internet storage tool, which is the product of Internet cloud technology. Not only teachers can use it, but also students can share their homework or materials, so that students can observe and learn from each other. Of course, there is also a kind of teaching software such as Superstar Learning System. In this system, the teacher can directly send the courseware into the system for students to see, at the same time can arrange and correct the homework, but also can call and communicate with students. However, this software also has some shortcomings, such as uploading and making courseware cumbersome and time-consuming steps, a single method to obtain students' performance in class. New Internet and software technologies allow teachers and students to communicate about learning content both in and out of class. It can be seen that in the postPC era, the "interactive" teaching method is gradually changing from real-time teaching to real-time and nonreal-time teaching.

\section{NOTES ON THE INNOVATIVE APPLICATION OF INTERACTIVE TEACHING MODE}

The innovative use of "interactive" teaching methods is to arrange the teaching stages of the course one by one (see Figure 2). Combined with the use of the Internet and software tools, "interactive" teaching mode can be used not only in the classroom, but also after the class can be used to teach students. Although teaching methods are varied and teaching contents are vividly displayed, there are still two points that teachers should pay attention to.

First, the use of wireless Wi-Fi connection for screen sharing is convenient for teachers and students in the teaching process, but if students are absent and not careful to observe the study during the teaching process, the learning efficiency will be reduced. This requires teachers to pay attention to the current situation of students' learning in the process of teaching, correct and guide students' learning attitude. Secondly, because the homework of computer costume drawing is to use the drawing software to make the costume effect drawing, if the students only hand in a picture as the homework, it does not indicate whether the students finished it independently.

Then, teachers need to ask students to retain the drawing layer or take a screenshot during the use of software as the production trace when drawing homework, and the teacher will give a score based on it. These precautions can strengthen the interaction between teachers and students, so that teachers can pay close attention to and understand the learning status of students, so as to meet teaching requirements.

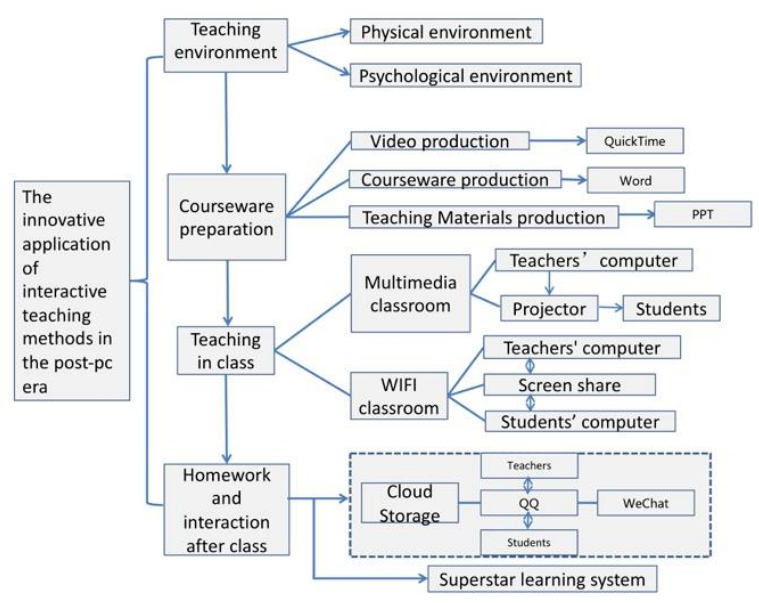

Figure 2. Interactive teaching innovative mode steps display diagram of computer

\section{CONCLUSION}

In the post-PC era, traditional "interactive" teaching methods are gradually undergoing innovative changes under the influence of technology and the products of the Internet. Teachers can choose different teaching methods according to different teaching requirements of the course. As the paper combining with teaching process, from the innovation of teaching environment, video production in preparation before class, class by software in real-time and non-real-time teaching methods in class interaction chat software and the use of the cloud storage, the "interactive" innovative teaching methods make course more vivid. At the same time, it can stimulate students learning initiative, improving students learning efficiency.

\section{AUTHORS' CONTRIBUTIONS}

Ning He conceived the idea of the study and wrote the paper; JiaYing Li translated the results; Yi Zhou had responsible for contacting; All authors discussed the results and gave the suggestions.

\section{ACKNOWLEDGMENTS}

We thank A.P. Bin Li for providing us the theme information and data. This paper is supported by Humanities and Social sciences Program of Department 
of Education of Hubei Province (19Q081), Education and Teaching Project of Wu Han Textile University (2015JY033).

\section{REFERENCES}

[1] LiLi Liu, Study of the "Interactive" teaching mode- Take the practical courses in product design as an example, Journal of Education on Teaching Forum, 2(2016)169-170

[2] YuanYuan Yao, DeQuan Li, Analysis and strategy of teaching interaction type in distance education, Journal of China Educational Technology \& Equipment,23(2013)35-37, DOI:10.3969/j.issn.1671-489X.2013.23.035

[3] HongYan Li, Lei Zhang, WenYan Zhao, Research on the Development of High Quality Curriculum Resources in Virtual Training Environment, Journal of Industrial Technology \& Vocational Education,18(2020)101-104, DOI: 10.16825/j.cnki.cn13-1400/tb.2020.04.028
[4] JianJun Jiang, RongJian Zhang, Shuang Yang, Design and implementation of the interactive video teaching platform based on WebRTC, Journal of Information Technology and Informatization, 12(2020)190-192, DOI: 10.3969/j.issn.16729528.2020.12.062

[5] ZhuoJian Guo, The advantages and prospects of informatization in international education, Journal of Information Technology and Informatization, 1(2021)217-218, DOI: 10.3969/j.issn.16729528.2021.01.066

[6] Bin $\mathrm{Li}$, Innovative practices in practical courses for computer software projects based on Huawei DevCloud, Journal of Information Technology and Informatization, 12(2019)30-32, DOI: doi:10.3969/j.issn.1672-9528.2019.12.008

[7] Xingxia Niu, Guilin Han, Research and Exploration of Presentation-Assimilation-Discussion Class Teaching Mode Under the Network Environment, Journal of Industrial Technology \& Vocational Education, $\quad$ 16(2018)26-28, DOI: 10.16825/j.cnki.cn13-1400/tb.2018.01.010 